\title{
Um ponto de situação do novo modelo editorial da revista
}

Alberto Pinto Hespanhol*

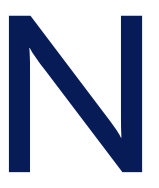

o Editorial da antepenúltima Revista Portuguesa de Medicina Geral e Familiar (RPMGF) com o título "A partilha do conhecimento num novo ciclo", ${ }^{1}$ o Dr. Rui Nogueira deu a conhecer a reformulação que a Direcção da Associação Portuguesa de Medicina Geral e Familiar (APMGF) pretende dar à RPMGF, especificando os motivos porque o fazem, quando se iniciará essa restruturação, quais as mudanças a realizar e em que moldes serão implementadas essas atividades.

Referiu estar aberto um novo ciclo, cuja preocupação principal é manter o rigor científico e a independência total e absoluta da Revista, com vista a alcançar a melhoria do seu fator de impacto, já há muito desejada, de modo a permitir a indexação da RPMGF nas melhores bases de dados de revistas científicas.

A outra mudança anunciada foi a separação de forma clara da função diretiva da função editorial, assumindo pelo seu lado a Direção da RPMGF e endereçando-me o convite para ocupar o lugar de Editor-chefe nos seguintes termos: “... A função editorial é assumida por uma equipa de colegas liderada por um Editor-chefe. ..."

Como referi no meu Editorial da última Revista, com o título "Contributo de novo modelo editorial da Revista para a Formação e a Investigação em Medicina Geral e Familiar", ${ }^{2}$ agradeci e aceitei ser o Editor-chefe da RPMGF, conduzindo os membros dos órgãos do Corpo Editorial como um maestro de uma organização baseada na estrutura não hierarquizada das orquestras sinfónicas. $^{3}$

Numa orquestra sinfónica, o "maestro", ou seja, o Editor-chefe, orienta a execução das obras musicais que tenham sido escolhidas; neste caso, o processo de revisão interpares dos artigos submetidos para publicação, com o acordo prévio dos "músicos", ou seja, dos diferentes membros dos órgãos do Corpo Editorial (Editores-

*Editor Chefe da Revista Portuguesa de Medicina Geral e Familiar -adjuntos, Conselho Editorial, Revisores, Conselho Científico e todos os profissionais incluídos na ficha técnica da Revista), os quais tem também de coordenar, imprimindo a intensidade e o ritmo que entender necessários. Como os "músicos" de uma orquestra sinfónica, cada profissional do Corpo Editorial atua de forma independente, interpretando as partituras com liberdade artística; neste caso, o fluxograma editorial (em anexo), de acordo com a sua criatividade. Contudo, devem integrar-se no conjunto com base na informação completa e verdadeira, em tempo real, de como todos os intervenientes estão a executar as suas tarefas e através do respeito absoluto de cada um por um conjunto de regras básicas comuns, nomeadamente a estrutura funcional da Revista e a plataforma Open Journal Systems (OJS). ${ }^{3}$

Num Corpo Editorial com um modelo organizativo do tipo orquestra sinfónica, o Editor-chefe terá necessariamente um comportamento de liderança democrático, centrado nos dirigidos, orientado para as relações humanas e em que o poder do líder é-lhe concedido pelo grupo que lidera. Se devidamente motivados, os indivíduos podem ser autodirigidos e criativos no trabalho.

Nesta liderança não diretiva, o líder partilha as suas responsabilidades de liderança com aqueles que dirige envolvendo-os no planeamento e execução das tarefas, em que as tomadas de posição são abertas à discussão e à decisão em grupo. ${ }^{4}$

Neste momento, a liderança que se espera do Editor-chefe, assessorado pelos dois Editores-adjuntos (Dr. Tiago Maricoto e Professor Paulo Santos), é que seja capaz de entender a situação que se pretende influenciar, de adaptar o seu comportamento e outros recursos disponíveis para irem ao encontro das contingências da situação e de comunicar de modo a que as pessoas possam facilmente compreender e aceitar. ${ }^{4}$

Por outras palavras, ter sempre em mente os conselhos de Ovretveit quando se pretende introduzir um Sistema para Assegurar a Qualidade numa Instituição 
AUTOR

\begin{tabular}{l}
\hline Submissbs \\
Autor submete o artipo peta \\
plataforma, holundo \\
metadados para indeacta
\end{tabular}

Arempanhamesto do

Precentio de Avaliacls

Astur é netilficato pol:

ecrotarie da cetura do

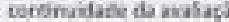

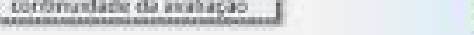

Reviaso da Submissso

Autor revb a revislo e fas

attereciles se solkaradas ao

arifo ou documentos

aneves

\section{EQUIPA EDITORIAL E SECRETARIADO}

Validarabo Mdministrativa

Secretario valida os reouls tos

do artago segundo as normas

da revista

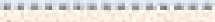

Secrutario axver aropo a

velioes chets

Avaliaçio Preliminar

O fiftar Chefe analisa o

Imbite de artike, dacidinde a

wa rectua cu centinuasto no

procenve de avaliaclo

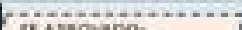

IT AHONDO:

cativictels mitud

artipe antarnin coegle :
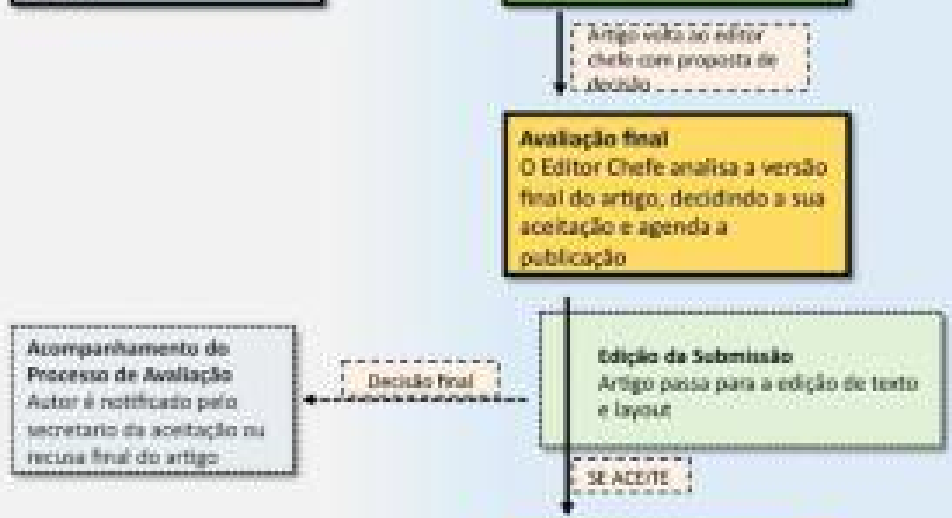

- xicents

Avaliasso da Submks5s

Edece de secchiso urienta.

arbias e pere codo o processs

de avaliacio

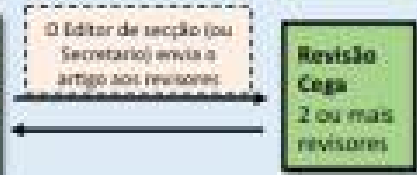

Ninhamento para publicachs

Q Editor Chele prepara o

atinhamento de cada ed çbo da

revisto, egendando o a tigo

Mevisise de Brova

aceite na awalaclo previa

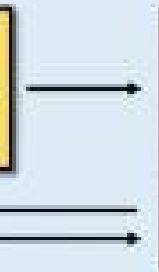

Aevisbo Térnica e

Paginaclo

Revislo thotica e

preparacto do

artigo nasua

verstle final de

puelicacle.

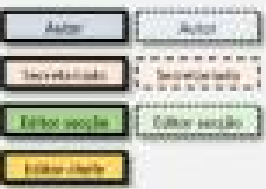


e que, passo a citar, ${ }^{5}$ "processos e pessoas perfeitas fazem um serviço de Qualidade (...) havendo Melhoria Contínua da Qualidade quando se dá ao pessoal as aptidões e os métodos necessários para analisar os problemas e os processos de qualidade e o poder para fazer as alterações necessárias...”. Por outro lado, “a má qualidade do serviço resulta de processos mal desenhados e mal aplicados e quase nunca de pessoal preguiçoso ou incompetente (...) a Qualidade não resulta simplesmente do estabelecimento de "Standards", inspeções e exortações ao pessoal...." ${ }^{5}$

Concluindo, a liderança do Editor-chefe da RPMGF consistirá no modo de influenciar as atividades do Corpo Editorial da RPMGF, visando alcançar os objetivos do novo modelo editorial da Revista, referidos pelo seu Diretor, Dr. Rui Nogueira, no seu último Editorial e por mim do seguinte modo:

- Manter o rigor científico e a independência total e absoluta

- Separar de forma clara a função diretiva da função editorial

- Fomentar a formação contínua de novos editores

- Incentivar a publicação on-line e a edição de artigos originais em inglês

- Promover a parceria para publicação de artigos originais em revistas de referência. ${ }^{2}$

Estes objetivos já foram iniciados, com exceção de "incentivar a publicação on-line e a edição de artigos originais em inglês".

Todos os Editores do anterior Corpo Editorial foram contactados pelo Editor-chefe no sentido de manterem a sua colaboração com a Revista, não tendo nenhum desejado continuar como Editor, mostrando-se, contudo, disponíveis para serem Revisores.
Perante esta situação decidimos contactar alguns colegas para se iniciarem já no processo editorial e na utilização da plataforma OJS, um software desenvolvido para a construção e gestão de publicações periódicas científicas, ficando todos convidados a frequentarem uma formação sobre as funções de um editor de uma Revista científica que avançará nos próximos meses.

Também foi enviado a todos os Revisores, que no momento presente colaboravam com a RPMGF, convite para manterem esta sua função, tendo já recebido um número expressivo de colegas disponíveis para continuarem nesse trabalho.

Embora já tivesse referido os meus agradecimentos a todos os Diretores da RPMGF e seus Corpos Editoriais que me antecederam desde a sua publicação em 1984, no meu Editorial da última Revista, ${ }^{2}$ não é demais voltar a expressar um muito obrigado pela colaboração, dedicação e empenho prestados à RPMGF por todos estes Editores e Revisores do anterior Corpo Editorial.

\section{REFERÊNCIAS BIBLIOGRÁFICAS}

1. Nogueira R.A partilha do conhecimento num novo ciclo [Sharing knowledge in a new cycle]. Rev Port Med Geral Fam. 2017;33(3):170. Portuguese

2. Hespanhol AP. Contributo de novo modelo editorial da revista para a formação e a investigação em medicina geral e familiar [Contribution of a new editorial model for contiuous education and research in general and family medicine]. Rev Port Med Geral Fam. 2017;33(4):242. Portuguese

3. Drucker PF. Peter Drucker on the profession management. Boston: The Harvard Business School Press; 1998. ISBN 9780875848365

4. Hersey P, Blanchard KH, Johnson DE. Management of organizational behaviour: utilizing human resources. 7th ed. New Jersey: Pearson; 1996. ISBN 9780132617697

5. Ovretveit J. Health service quality: an introduction to quality methods for health services. Oxford: Blackwell Scientific Publications; 1992. ISBN 0632032790 